among children aged 11-15 years; (2) To examine the combined effects of physical fighting and weapon carrying on the occurrence of physical and emotional health outcomes among adolescents.

Methods 20125 adolescents aged 11-15 in five countries (Belgium, Israel, USA, Canada, FYR Macedonia) were surveyed via the 2006 Health Behaviour in School Aged Children survey. Prevalence was calculated for measures of violence (physical fighting, weapon carrying). Reports of specific physical (medically treated injury) and emotional symptom measures that represented potential health outcomes of violence were also assessed. Regression analyses were used to quantify associations between violence and the potential health consequences within each country.

Results Large variations in fighting and weapon carrying were observed across the countries. Boys reported more frequent episodes of violent behaviour and medically attended injuries in every country, while girls reported more emotional symptoms. Increased weapon carrying and physical fighting were both independently associated with more frequent reports of the health outcomes (eg, OR point estimates 1.7 to 4.5; $\mathrm{p}<0.0001)$, but those adolescents engaged in both behaviours were not proportionally at increased risk.

Conclusions Adolescents engaging in violent behaviour are also at risk for physical and emotional health outcomes. Violent behaviour may be part of a constellation of risk behaviours with health implications. Our findings also highlight the importance of the cultural context when examining the nature of violent behaviour for adolescents.

\section{PHYSICAL AND EMOTIONAL HEALTH PROBLEMS EXPERIENCED BY YOUTH ENGAGED IN VIOLENT BEHAVIOUR}

S Walsh, M Molcho, Y Harel-Fisch, 0 Huynh, A Kukaswadia, K Aasvee, D Varnai, V Ottova, U Ravens-Sieberer, W Pickett* Correspondence: Queen's University, Emergency Medicine Research, Kingston General Hospital, 76 Stuart St., Kingston, ON K7L 2V7, Canada

10.1136/ip.2010.029215.233

Purpose (1) To provide contemporary cross-national estimates of the prevalence of physical fighting and weapon carrying 